\title{
Application of AHP-Ansoff Matrix Analysis in Business Diversification: The case of Evergrande Group
}

\author{
Nan Yin ${ }^{1, a}$ \\ ${ }^{1}$ Business School, Nanjing Xiaozhuang University, Nanjing City, China
}

\begin{abstract}
A new method of enterprise strategic research, the AHP-Ansoff Matrix analysis method, is put forward in this paper for the first time and applied in the enterprise practices. By using this research method, the development strategy of enterprise diversification is analyzed scientifically and reasonably with Evergrande group as the example. And finally, main procedures of the method are summarized.
\end{abstract}

\section{INTRODUCTION}

Diversified development strategy is a kind of enterprise development strategy chosen by the enterprise in order to maximize profit and occupy more market, which is generally suitable for large enterprises with great financial strength, large scale of development and significant market share. Regarded as one aspect of the enterprise strategic decision research, the study of enterprise diversification strategy is currently studied by several domestic experts and scholars in the following aspects:(1)the relationship between enterprise diversification strategy and business performance. Zhao Feng[1], the scholar from Harbin Industrial University concluded that the enterprise diversification strategy had a significant negative effect on business performance of enterprises based on sample data of the real evidence; With the method of questionnaire survey, Zou Hao[2], the scholar from Northeastern University concluded that the diversification strategy was as a function of enterprise business performance, different analytical functions could be acquired according to different types of diversification strategy, and then on the basis of the function, the corresponding enterprise performance value could be found.(2)the relationship between diversification strategy and enterprise's technological capabilities. Liu Hongwei[3], the scholar form Xiangtan University has conducted empirical research on the related samples, the results of which showed that enterprise diversification strategy went against the promotion of enterprise's technological capabilities, and the negative effect brought by can by diversification strategy could be weakened by enhancing the technological research and development.(3)the relationship between diversification strategy and characteristics of entrepreneurs. Cheng Chuanming[4], the scholar from Nanjing University verified the relationship between entrepreneurs' personal background characteristics and diversification strategy based on the panel data of public companies, the results indicating that educational background of the entrepreneur was in positve correlation with the degree of enterprise diversification, the degree of enterprise diversification would be higher if entrepreneur had a technical background, and the degree of enterprise diversification would be lower if entrepreneur had a financial background.(4)the relationship between enterprise diversification strategy and the choice of target industry. Lan Weiguo[5], the scholar from Beijing University of Technology studied the correlation of diversification strategy and industry life cycle, and methods to recognize and evaluate enterprise diversification industry.

Above all, nowadays, the study of enterprise diversification strategy conducted by domestic experts and scholars were mainly limited to the relevance of enterprise diversification development strategy and enterprise business performance, enterprise technological capabilities and entrepreneurs' characteristics, lacking of relevant research methods about how to implement the strategy of diversifying effectively and how to choose suitable diversification strategy for the enterprise's development. This paper puts forward a new method of enterprise strategic research, the AHP-Ansoff Matrix analysis method that is innovative and practical. This method was applied in the enterprise practices, and can effectively analyze the enterprise diversification development strategy.

\section{THE PRINCIPLE OF ANSOFF MATRIX ANALYSIS}

Ansoff Matrix, also named Product Market Expansion Grid or Growth Vector Matrix, is a research method applied in the analysis of products and markets, which was proposed by Ansoff, the father of strategic

\footnotetext{
a Corresponding author: kitupfor@163.com
} 
management in 1975[6]. This method can be used to analyze the thoughts for enterprise to expand the market and develop new products more objectively and accurately, and is extensively applied in enterprise strategic management. The matrix analysis is composed of four research strategies — new products strategy, existing products strategy, new market strategy and the existing market strategy. For an enterprise implementing diversification strategy, it is faced with fierce competition in terms of market and products both. Therefore, the analysis of the four research strategies has an important significance on the enterprise strategy.

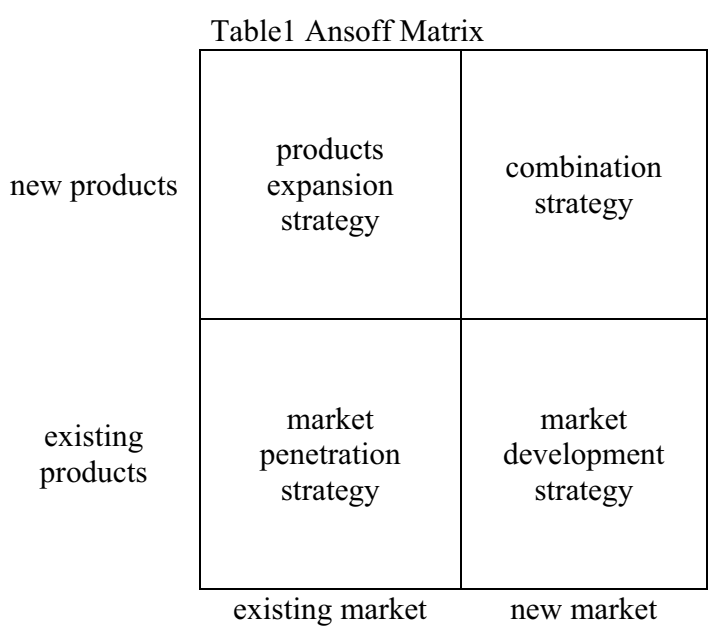

Table 1 is the base form of Ansoff Matrix. Ansoff matrix can help enterprise manager to implement strategy mode in a scientific and effective way, and the basic application procedures of Ansoff Matrix are as follows:

Enterprises consider whether the existing products in the existing market can get more market share (market penetration strategy);

Enterprises consider whether new market can be developed for the existing products (market development strategy)

Enterprises consider whether new products can be developed for the existing market to satisfy the need of more customers (products expansion strategy);

Enterprises consider whether new products and new market can be developed by making full use of the advantages in products, technology and market, which is a comprehensive strategy to enable enterprise to develop in multi-levels and all aspects (combination strategy).

\section{ESTABLISHMENT OF ANSOFF MATRIX ANALYSIS}

Evergrande group is a large enterprise implementing the strategy of diversified development, with real estate as the main business. According to its website (http://www.evergrande.com), Evergrande group is an enterprise group with the integration of residential buildings, cultural tourism, fast-moving consumer products, health and sports, covering extensive diversified development business. So, Evergrande group is taken as an example in this paper to conduct relevant research on diversified business development strategy, which has certain feasibility and practical significance.

The strategy of diversified development carried out by enterprises is counter to the single specialized business strategy implemented by other enterprises. According to the principle of Ansoff Matrix analysis, table 2 establishes diversification business development strategy for Evergrande group based on four research strategies of Ansoff Matrix .

Table 2 Ansoff analysis matrix of diversification business development strategy for Evergrande group

\begin{tabular}{|c|c|c|}
\hline $\begin{array}{c}\text { Target } \\
\text { hierarchy }\end{array}$ & $\begin{array}{l}\text { Criterion } \\
\text { hierarchy }\end{array}$ & Index hierarchy \\
\hline \multirow{4}{*}{$\begin{array}{l}\text { diversificatio } \\
\mathrm{n} \text { business } \\
\text { development } \\
\text { strategy for } \\
\text { Evergrande } \\
\text { group (A) }\end{array}$} & $\begin{array}{c}\text { new } \\
\text { products } \\
\text { (B1) }\end{array}$ & $\begin{array}{l}\text { X1 fast-moving consumer } \\
\text { products } \\
\text { X2 health and medical products } \\
\text { X3 The internet community } \\
\text { service products } \\
\text { X4 video and musical products } \\
\text { X5 sports related products }\end{array}$ \\
\hline & $\begin{array}{l}\text { exsiting } \\
\text { products } \\
\text { (B2) }\end{array}$ & $\begin{array}{l}\text { X6 products of residential } \\
\text { buildings } \\
\text { X7 products of commercial real } \\
\text { estate } \\
\text { X8 products of hotel industry } \\
\text { X9 products of cultural tourism }\end{array}$ \\
\hline & $\begin{array}{c}\text { new } \\
\text { market } \\
\text { (B3) }\end{array}$ & $\begin{array}{l}\text { X10 market of fast-moving } \\
\text { consumer products } \\
\text { X11 market of high-end health } \\
\text { industry } \\
\text { X12 market of internet } \\
\text { community service } \\
\text { X13 market of film and } \\
\text { television relevant industry } \\
\text { X14 market of football and } \\
\text { volley industry }\end{array}$ \\
\hline & $\begin{array}{c}\text { exsiting } \\
\text { market } \\
\text { (B4) }\end{array}$ & $\begin{array}{l}\text { X15 market of residential } \\
\text { buildings } \\
\text { X16 market of commercial real } \\
\text { estate } \\
\text { X17 market of hotel industry } \\
\text { X18 market of cultural tourism }\end{array}$ \\
\hline
\end{tabular}

The above is the establishment of Ansoff analysis matrix of diversification business development strategy for Evergrande group, the relative importance of each factor in each hierarchy can be judged with the combination of Analytic Hierarchy Process (AHP) and the AHP method is adopted to calculate the coefficient of relative importance.

\section{HIERARCHICAL RANKING AND CONSISTENCY TEST ON THE BASIS OF AHP}

\subsection{The principle of AHP method}


Proposed by American operations researcher A.L.Saaty in the 1970s, Analytical Hierarchy Process (the AHP method) is a combinative method of qualitative and quantitative decision analysis. It is a type of modelizing and quantifying process for complex decision-making thoughts of the decision maker. The basic procedures of analysis are as follows [7]:

(1) Establishment of hierarchical structure model. On the basis of in-depth analysis of the actual problems, all the relevant factors are decomposed into several hierarchies from top to bottom according to different attributes and are concluded into groups according to whether sharing some common characteristics. The common characteristics between them are considered as factors in the new hierarchy of the system, and according to additional characteristics, these factors themselves are integrated to form factors of a higher hierarchy, until factors of the single highest hierarchy are finally formed.

(2) Establishment of judgment matrix 。Judgment matrix compares the relative importance between the certain unit (element) of the previous hierarchy and the related unit of this hierarchy. The value of each element in the judgment matrix is determined by $1 \sim 9$ digit scale method[8] and obtained mainly through expert evaluation or historical data (experience). Quantity scale of assessment in different situation is given and the basic rules are shown in table 3 .

Table $31 \sim 9$ scale method

\begin{tabular}{|c|l|}
\hline Scale & \multicolumn{1}{|c|}{ Definition and Explanation } \\
\hline 1 & $\begin{array}{l}\text { two elements have equal importance to certain } \\
\text { attribute }\end{array}$ \\
\hline 3 & $\begin{array}{l}\text { two elements compare, and one element is slightly } \\
\text { more important than the other }\end{array}$ \\
\hline 5 & $\begin{array}{l}\text { two elements compare, and one element is obviously } \\
\text { more important than the other }\end{array}$ \\
\hline 7 & $\begin{array}{l}\text { two elements compare, and one element is much } \\
\text { more important than the other }\end{array}$ \\
\hline 9 & $\begin{array}{l}\text { two elements compare, and one element is extremely } \\
\text { more important than the other }\end{array}$ \\
\hline $2,4,6$, & $\begin{array}{l}\text { representing the scale compromised between two } \\
\text { standards above }\end{array}$ \\
\hline $1 / b_{i j}$ & \begin{tabular}{l} 
converse comparison of two elements \\
\hline
\end{tabular} \\
\hline
\end{tabular}

(3) Weight vector is calculated and consistency test is conducted. The relative weight of each factor in every judgment matrix to its criterion is calculated. The correspondent eigenvector $\mathrm{W}$ of judgment matrix $\mathrm{A}$ to maximum eigenvalue is normalized to obtain importance rank weights of the correspondent factors in the same hierarchy to the certain factor in previous hierarchy. To avoid interference of other factors on the judgment matrix, in reality, the judgment matrix is required to meet the general consistency and a consistency test is needed. Only by passing the test, the judgment matrix is proved to be reasonable in logic, and the results can be further analyzed.

To test the consistency of judgment matrix, calculate:

$\mathrm{CR}=\mathrm{CI} / \mathrm{RI}$
In formula (1), $\mathrm{CR}$ represents consistency ratio. If $\mathrm{CR}<0.10$, the consistency of judgment matrix is acceptable. Otherwise, the judgment matrix should be adjusted properly. CI represents consistency index and is calculated as the follow formula:

$$
\mathrm{CI}=(\lambda \max -\mathrm{n}) /(\mathrm{n}-1)
$$

In formula (2), $\lambda \max$ is the maximum eigenvalue of the judgment matrix; $\mathrm{n}$ is the number of the comparative factor in pairs; RI represents random index.

\section{2. analysis and calculating process}

(1) Establishment of hierarchy structure model

As table 2 illustrates, establishment of hierarchy structure model for diversification business development strategy of Evergrande group could be descried as follows:

The target hierarchy (the highest hierarchy): diversification business development strategy of Evergrande group (A);

The criterion hierarchy (the middle hierarchy): new products (B1), existing products (B2), new market (B3), existing market (B4);

The index hierarchy (the bottom hierarchy): index X1 to $\mathrm{X} 18$ in table 2 .

(2)Establishment of judgment matrix and consistency test

The judgment matrix is established and the four factors in the target hierarchy and the criterion hierarchy are compared in pairs. The four factors in the criterion hierarchy are compared with their factors in the index hierarchy in pairs, and through calculation the weights of the four factors in the criterion hierarchy-new products (B1), existing products (B2), new market (B3), existing market (B4) versus the target hierarchydiversification business development strategy of Evergrande group (A) are 0.125, 0.250, 0.125 and 0.500, respectively. And the calculation results of weights of the other indexes versus their factors in the criterion hierarchy are shown in Table 4 , and pass the consistency test with the result of $\mathrm{CR}<0.10$.

Table 4 single ordering weight value of hierarchies

\begin{tabular}{|l|l|l|l|l|l|l|}
\hline $\begin{array}{l}\text { Mat } \\
\text { rix }\end{array}$ & $W_{1}$ & $W_{2}$ & $W_{3}$ & $W_{4}$ & $W_{5}$ & $\begin{array}{l}\text { CR } \\
\text { test }\end{array}$ \\
\hline $\mathrm{A}$ & 0.125 & 0.250 & 0.125 & 0.500 & & 0 \\
\hline$B_{1}$ & 0.455 & 0.181 & 0.195 & 0.099 & 0.070 & 0.022 \\
\hline$B_{2}$ & 0.437 & 0.210 & 0.220 & 0.133 & & 0.020 \\
\hline$B_{3}$ & 0.341 & 0.130 & 0.325 & 0.123 & 0.081 & 0.032 \\
\hline$B_{4}$ & 0.422 & 0.152 & 0.236 & 0.190 & & 0.059 \\
\hline
\end{tabular}

According to the results of single ordering weight value of hierarchies in Table 4 and the importance degree of the evaluation ability, the relative importance degree of all factors versus total target is calculated from top to bottom hierarchy by hierarchy and the results are shown in table 5. The diversification business development strategy of Evergrande group is analyzed systematically 
with Analytic Hierarchy Process method and the ranking of importance degree of each factor in index hierarchy (X1 to X18) versus the target hierarchy is shown in Figure 1.

Table 5 total ordering weight value of hierarchies

\begin{tabular}{|l|l|l|l|l|l|}
\hline Matrix & $W_{1}$ & $W_{2}$ & $W_{3}$ & $W_{4}$ & $W_{5}$ \\
\hline$B_{1}$ & 0.050 & 0.007 & 0.020 & 0.032 & 0.016 \\
\hline$B_{2}$ & 0.092 & 0.104 & 0.035 & 0.019 & \\
\hline$B_{3}$ & 0.042 & 0.012 & 0.028 & 0.014 & 0.029 \\
\hline$B_{4}$ & 0.213 & 0.098 & 0.131 & 0.058 & \\
\hline
\end{tabular}

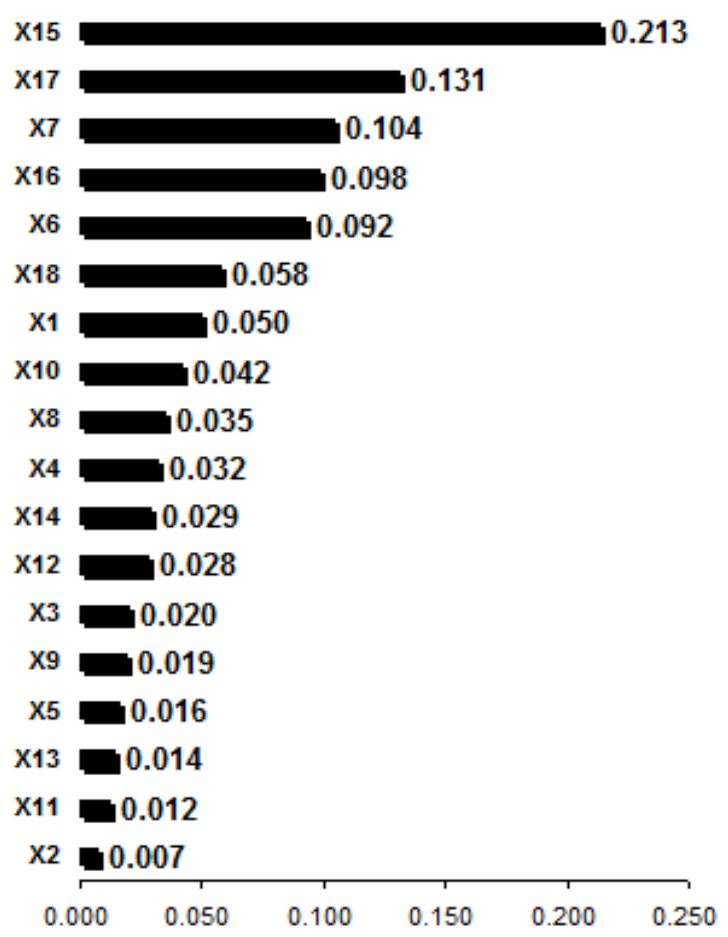

Figure 1 the weight ranking of each factor in the index hierarchy

\section{Diversification business development strategy and measures of Evergrande group}

Based on the results of calculation and analysis above, the diversification business development strategy of Evergrande group is analyzed systematically. The relative importance of all factors in the process of diversification business development of Evergrande group is ranked; the ranking results indicate that the effect degree of each factor in the process of diversification business development of Evergrande group is of great difference. To highlight the major factors, four factors in the criterion hierarchy_ new products (B1), existing products (B2), new market (B3), existing market (B4) is integrated with four research strategies in the Ansoff Matrix analysis diagram to figure out the maximum importance of each research strategy, namely to find out the highest index value of weight for each index of the four factors in the criterion hierarchy, and the results are $\mathrm{X} 1=0.050, \quad \mathrm{X} 7=0.104, \quad \mathrm{X} 10=0.042, \quad \mathrm{X} 15=0.213$. The representative results of total ranking of these hierarchies are marked in the Ansoff Matrix analysis diagram and are linked into a quadrangle in sequence and in the form of coordinate axis, as shown in Figure 2.

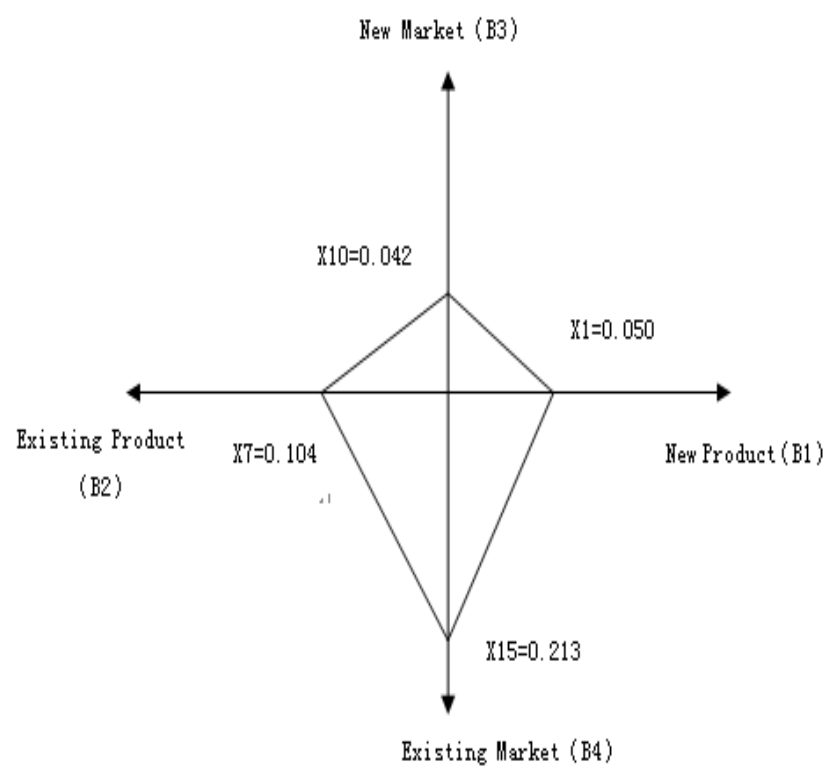

Figure 2 Ansoff Matrix analysis methods for diversification business development strategy of Evergrande group

The calculation results of triangle size of each quadrant in the coordinate axis of figure 2 are: triangle size of B1-B3 quadrant $=0.00105$, triangle size of $\mathrm{B} 2-\mathrm{B} 3$ quadrant $=0.002184$, triangle size of B2-B4 quadrant $=0.011076$, and triangle size of B1-B4 quadrant $=0.005325$. The triangle size of each quadrant is compared and the result indicates that triangle size of B2$\mathrm{B} 4$ quadrant $>$ triangle size of $\mathrm{B} 1-\mathrm{B} 4$ quadrant $>$ triangle size of B2-B3 quadrant $>$ triangle size of B1-B3 quadrant. Combined with Ansoff Matrix analysis method, the sequence for diversification business development strategy of Evergrande group is market penetration strategy, products expansion strategy, market development strategy and combination strategy.

In accordance with the calculation results and Ansoff Matrix analysis method in figure 2, further analysis could be conducted on the four diversified development strategies chosen by Evergrande group.

(1) Market penetration strategy. Market penetration strategy is an enterprise development strategy to fully develop its existing market potential based on the existing main products. It is the most important strategy for Evergrande group since Evergrande group started as a real estate company and then grew into an enterprise of diversified development and real estate industry remains the main business and major source of profits. Therefore, when adopting diversified development strategies, the main business direction is still to attach great importance to the existing products, such as products of residential buildings and products of commercial real estate; meanwhile, develop the potential of existing market, for example, the major markets of Evergrande group are still first-tier cities like Beijing, Shanghai, Guangzhou and Shenzhen ect.. Some commercial real estate projects 
could be developed in the suburb with development potential in the future which is far from the main urban zone.

(2) Products expansion strategy. The products expansion strategy is to expand the scale of sales by improving existing products or developing new products in the existing market. It is the second important strategy after market penetration strategy for diversification development strategy of Evergrande group. When Evergrande group applies diversification business development strategy, it will strengthen its main market of real estate industry and develop some new products based on the industry to maintain of the main market on the one hand and expand the sales scale of the main market. For example, Evergrande group launched new product of mineral water, Evergrande spring, and introduced it into the supply system of direct drinking water for Evergrande Real Estate, thus sales of residential building industry was promoted.

(3) Market development strategy. Market development strategy is that enterprises develop new markets with existing products. When Evergrande group chooses diversification business development strategy, it can develop new markets with existing products on the basis of strengthening its main market. By applying this strategy, Evergrande group could expand the sales scale for existing products and find opportunity for profits in the new market. The existing products of Evergrande group are mainly related to real estate industry, such as products of residential building, products of commercial real estate and products of hotel industry ect.. Under the condition that real estate industry of first-tier cities likes Beijing, Shanghai, Guangzhou and Shenzhen ect. is trending towards saturation gradually, Evergrande group could march into the second-tier and third-tier cities to develop the markets of residential building and commercial real estate in these medium and small-sized cities.

(4) Combination strategy. Combination strategy is that enterprises develop new products in new market to maximize the profit. Since this strategy means developing new products in new market to satisfy target consumers, so enterprises should consider carefully and conduct adequate preliminary market research before implementing this enterprise development strategy. Owing to the great financial strength of Evergrande group, when taking the diversified development strategies it develop several new products that are not relevant to its main business in many potential emerging markets, for example, Evergrande group has acquired one of South Korea's largest plastic surgery hospital to march into the market of plastic surgery in China, and now Evergrande group has opened up its first plastic surgery hospital in the city of Tianjin.

\section{Conclusions}

This paper utilizes a new research method of enterprise strategy_-AHP_Ansoff Matrix analysis method to analyze the possible strategy decision for Evergrande group to carry out diversification business development strategy scientifically with Evergrande group as the example. Based on the analytical results above, this research method for enterprise strategy is proved to be effective and the results indicate that when Evergrande group develop diversified business, the diversified business strategy to choose is to focus on the main business of real estate industry and gradually develop other markets and new products. And the enterprise's development strategy should focus on market penetration strategy and products expansion strategy and gradually implement market development strategy and combination strategy.

For the analysis procedures above, the application steps of AHP-Ansoff Matrix analysis method can be summarized as follows: (1) Establish Ansoff Matrix analysis for enterprise diversification business development strategy. (2) Establish hierarchy structure model for enterprise business development strategy on the basis of Analytic Hierarchy Process (AHP). (3) Judge the importance of each factor in every hierarchy to obtain the total ordering weight value of hierarchies and rank the orders of each factor in the criterion hierarchy. (4) Integrate with four research strategies in the Ansoff Matrix analysis diagram to figure out the maximum importance of each research strategy, namely to find out the highest index value of weight for each index of the four factors in the criterion hierarchy. (5) The representative results of total ranking of these hierarchies are marked in the Ansoff Matrix analysis diagram and are linked into a quadrangle in sequence and in the form of coordinate axis. (6) Obtain the results to choose for enterprise business strategy and conduct further analysis.

\section{References}

[1]Zhaofeng, Wang Tienan, Zhangliang. The Effect of Diversification Strategy on Enterprise's Performance Based on Study with Real Evidence. China Soft Science,2012, (11):111-122.

[2]Zouhao, Yang Xihuai, Cai Jinzheng. The Relationship between Diversification Strategy and Enterprise's Performance. Economic Management,2007,29(11):12-16. [3]Liu Hongwei, He Meili. Effect Study of Diversification Strategy on Enterprise's Technological Capabilities. Soft Science,2015,29(8):61-65.

[4]Chen Chuanming, Sun Junhua. Entrepreneurs' Personal Background Characteristics and the Choice of Diversification Strategy. Management World,2008, (5):124-188.

[5]Lan Weiguo, Zhang Yongan, Yangli. Study on Enterprise's Diversification Strategy and the Choice of Target Industry. Soft Science,2009,23(4):7-12.

[6]Igor Ansoff. Strategy Management.Beijing: China Machine Press,2013.

[7]Qian Songdi. Operations Research (the third edition). Beijing: Tsinghua University Press, 2005 .

[8]Zhang Bingjiang. Analytic Hierarchy Process and Application Cases. Beijing: Publishing House of Electronics Industry,2014. 